\title{
ICONOGRAFIA COMO NARRATIVA ESTÉTICO-VISUAL DO SAGRADO NA AMAZÔNIA PARAENSE.
}

\author{
Marcos Murelle Azevedo Cruz ${ }^{1}$ \\ Flavio Leonel Abreu da Silveira ${ }^{2}$
}

\begin{abstract}
RESUMO
A pesquisa objetiva apresentar o conceito de iconografia como narrativa estético-visual do sagrado, no âmbito de uma arte litúrgica de tradição católica oriental a partir de registros imagéticos presentes na Amazônia. Considera que as imagens são formas artísticas de comunicação sobre algumas realidades, que trazem em si uma superação da linguagem literal para uma linguagem interpretada de uma determinada cena (de algum lugar) ou contexto. O conhecimento do contexto histórico-cultural em que a obra foi produzida desempenha um papel determinante, pois o sagrado com seus ritos e liturgias se constituem dentro de uma história não metafórica, na pervivência de seu sentido originário porque sobrevivem através das gerações vindouras. (BENJAMIN, 2008). Desse modo, o método iconográfico se inscreve na intersemiologia, e se refere à análise literária, no estudo das linguagens e de seus significados; na interpretação da cultura; na decodificação de seus significados; estabelece diálogo entre a palavra e a imagem; evidenciam relações de normas que tipificam e sistematizam seus símbolos e significados. Ao analisar a imagem e as linguagens por ela produzidas, a iconografia se pretende como método que procura construir perspectivas teóricas de análise da realidade por um olhar suspeitável das obras, haja vista sua vinculação a realidade social. Presentes na Amazônia, essas obras sobrevivem ao longo das épocas e sua permanência subsiste em expressões artísticas principalmente nos mosaicos. Por elas é possivel estabelecer diálogo com as diversas territorialidades da Amazônia, em seus rituais e em suas liturgias.
\end{abstract}

Palavras- chave: Iconografia. Imagem. Tradução Cultural.

\begin{abstract}
The research aims to present the concept of iconography as an aesthetic-visual narrative of the sacred, within the framework of a liturgical art of Eastern Catholic tradition based on imagery records present in the Amazon. It considers that the images are artistic forms of communication on some realities, that bring in themselves an overcoming of the literal language for a language interpreted of a certain scene (of somewhere) or context. The knowledge of the historical-cultural context in which the work was produced plays a decisive role, since the sacred with its rites and liturgies are constituted within a nonmetaphorical history, in the survival of its original sense because they survive through the generations to come. (BENJAMIN, 2008). In this way, the iconographic method is inscribed in intersemiology, and refers to literary analysis, in the study of languages and their meanings; In the interpretation of culture; In the decoding of their meanings; Establishes dialogue between word and image; Evidences relationships of norms that typify and systematize their symbols and meanings. In analyzing the image and the languages produced by it, iconography is intended as a method that seeks to construct theoretical perspectives of analysis of reality by a suspicious view of works, given their linkage to social reality. Present in the Amazon, these works survive throughout the ages and their permanence subsists in artistic expressions mainly in the mosaics. Through them it is possible to establish dialogue with the various territorialities of the Amazon, in their rituals and in their liturgies.
\end{abstract}

\footnotetext{
${ }^{1}$ Discente no Programa de Pós-Graduação em Linguagens e Saberes na Amazônia - PPLSA/UFPA, Campus de Bragança-Pa; e-mail: marcosmurelle@ gmail.com.

${ }^{2}$ Antropólogo e Professor Adjunto da UFPA - Campus Bragança; e-mail: flabreu@ufpa.br
} 
KEYWORDS: Iconography; Image; Cultural Translation.

Recebido em: 21/04/ 2017

Aprovado em: 10/05/2017

\section{CONSIDERAÇÕES INICIAIS}

O presente artigo integra o conjunto de discussões auxiliares à pesquisa sobre a arte bizantina na arquitetura da Amazônia, que é desenvolvido no âmbito da linha de pesquisa leitura e tradução cultural, do Programa de Pós-graduação em Linguagens e Saberes da Amazônia da UFPA.

O estudo situa-se na compreensão dos processos de tradução cultural, no âmbito da história da arte, e concentra-se na elaboração de perspectivas teóricas sobre iconografia em Erwin Panofsky e autores correlatos como método interpretativo das representações do sagrado no imaginário católico da Amazônia. Constituiu como objeto de análise o mosaico ${ }^{3}$ de tradição artística oriental ${ }^{4}$ que compõe o afresco do altar central da Catedral Diocesana de Castanhal, no estado do Pará.

Compreende-se por iconografia o estudo das imagens; eikon significa imagem, figura, representação; graphein - escrever, compor, designar, registrar. Desse modo, a iconografia pode ser considerada como uma vertente da história da arte que aborda o tema ou a mensagem das obras de arte em contraposição à sua forma [...] o significado assim percebido é de natureza elementar e facilmente compreensível e passaremos a chamá-lo de significado fatual [...] os objetos assim identificados produzirão, naturalmente uma reação em mim. (PANOFSKY, 2011, pág. 47-48).

Casimiro (2003) considera de modo preliminar que o método proposto por Panofsky não capta em sua inteireza as técnicas de interpretação, apenas uma parte delas, pois como

\footnotetext{
${ }^{3} \mathrm{O}$ mosaico é um conjunto de desenhos estilizados formados de cubos grandes e brilhantes e de vidros coloridos com superfícies irregulares. Quando geometricamente combinadas estas pedrinhas formam temas religiosos presentes nas narrativas bíblicas, p.ex: a ressurreição de Jesus e a sua descida ao mundo dos mortos. Trata-se de uma arte característica de tradição católica oriental.

${ }^{4} \mathrm{O}$ termo oriental refere-se à localização histórico-geográfica da Igreja Católica de Rito Oriental, bem como a produção de todo o seu patrimônio artístico-cultural, e faz referencia ao Cisma do Oriente em 1054, quando houve a separação entre Igreja Católica do Ocidente com sede em Roma e a Igreja Católica do Oriente sediada no Egito e em Constantinopla, na antiga Istambul. Ademais, versões históricas mostram que com a separação entre as igrejas, se acentuaram o distanciamento das práticas religiosas pelas duas vertentes do catolicismo. Além do mais, no momento em que o Império Romano do Ocidente (Roma) assistia sua falência total, o Império Romano do Oriente (Constantinopla) se fortalecia seja por sua organização politico-administrativa, seja pela sua produção artístico-cultural. É nesse contexto que ocorre o distanciamento de uma concepção teológica do Jesus Histórico como ser espiritual e a negação da concepção de natureza humana de Cristo elaborada pela tradição do Ocidente. A partir de então, inaugura-se uma desconfiança às imagens porque se acreditava que representava uma idolatria, dando lugar à valorização do aspecto espiritual dos mosaicos e dos ícones. Por diversos modos, essa arte chegou à Amazônia, e pode ser encontrado na Catedral Diocesana de Castanhal, Pará.
} 
etapas de um processo analítico, não realizam, nem contemplam, qualquer referência a uma outra vertente da análise que se pode e deve efetuar sobre as obras de arte, em particular sobre a pintura: a componente geométrica. Ademais, o processo de análise contextualizada das imagens trazem outros elementos importantes na interpretação como é o caso da relação que os expectadores estabelecem com o mosaico, das redes de significados e sentidos que são gerados a partir do movimento do sujeito que contempla a obra, e que transforma esta contemplação em palavras.

Assim, o método iconográfico se inscreve na intersemiologia, pois se refere à análise literária no estudo das linguagens e de seus significados; na interpretação da cultura; na decodificação de seus significados; estabelece diálogo entre a palavra e a imagem; estabelecem relações de normas que tipificam e sistematizam seus símbolos e significados. Desse modo, ao analisar a imagem e as linguagens por ela produzidas, a iconografia se pretende como método que procura construir perspectivas teóricas de análise da realidade por um olhar suspeitável da realidade das obras, tendo em vista que toda a expressão artística está vinculada a dimensões da vida social.

Em todo o caso, para aproximar-nos do entendimento e das motivações que levaram o artista a construir o mosaico, e do conjunto de significados que encerram a presença de uma intencionalidade artística de suas obras, proceder-se-á a leitura iconográfica e a interpretação iconológica do mosaico que é composto por quatro momentos importantes: 1) Anunciação do Anjo a Maria, 2) A crucificação de Jesus, 3) A deposição de Jesus da Cruz, e a 4) Descida de Jesus aos Ínferos. Todavia, para este trabalho serão analisadas somente as imagens 1 e 2.

\section{1-O LÓCUS E O OBJETO DE PESQUISA}

Como se sabe, a cidade de Castanhal está situada na região nordeste do Pará. Atualmente tem uma população estimada em 192.571 habitantes, destes 33489 se autodeclararam católicos apostólicos romanos, segundo dados do último Censo do IBGE. ${ }^{5}$ Nesta região está situada a Diocese de Castanhal, uma circunscrição eclesiástica da Igreja Católica no Brasil, criada pelo Papa João Paulo II em 29 de Dezembro de 2004, e seu Bispo Diocesano é D. Carlos Verzeletti. E para receber a sede da Diocese foi erigida uma Igreja Catedral em homenagem à Santa Maria, Mãe de Deus, donde foram arquitetadas várias obras tanto no interior como para o exterior da catedral.

\footnotetext{
${ }^{5}$ Censo Demográfico do IBGE. Disponível em <http://cod.ibge.gov.br/1H0A>. Acesso em 22/02/2017.
} 
Neste contexto surge o mosaico de tradição artística que foi projetado na abside do altar central da Igreja. Trata-se uma de uma obra encomendada pelo bispo diocesano D. Carlos Verzeletti ao Pe. Marko Ivan Rupnik, sacerdote jesuíta, de origem eslovena, teólogo e artista. O conjunto da obra narra momentos considerados importantes no contexto da narrativa bíblica sobre os principais momentos da vida do Jesus Histórico, fatos que encerram o ponto mais alto da mensagem cristã.

Fig. 1 - Mosaico, na abside do altar central da Igreja Catedral da Diocese de Castanhal, no Estado do Pará.

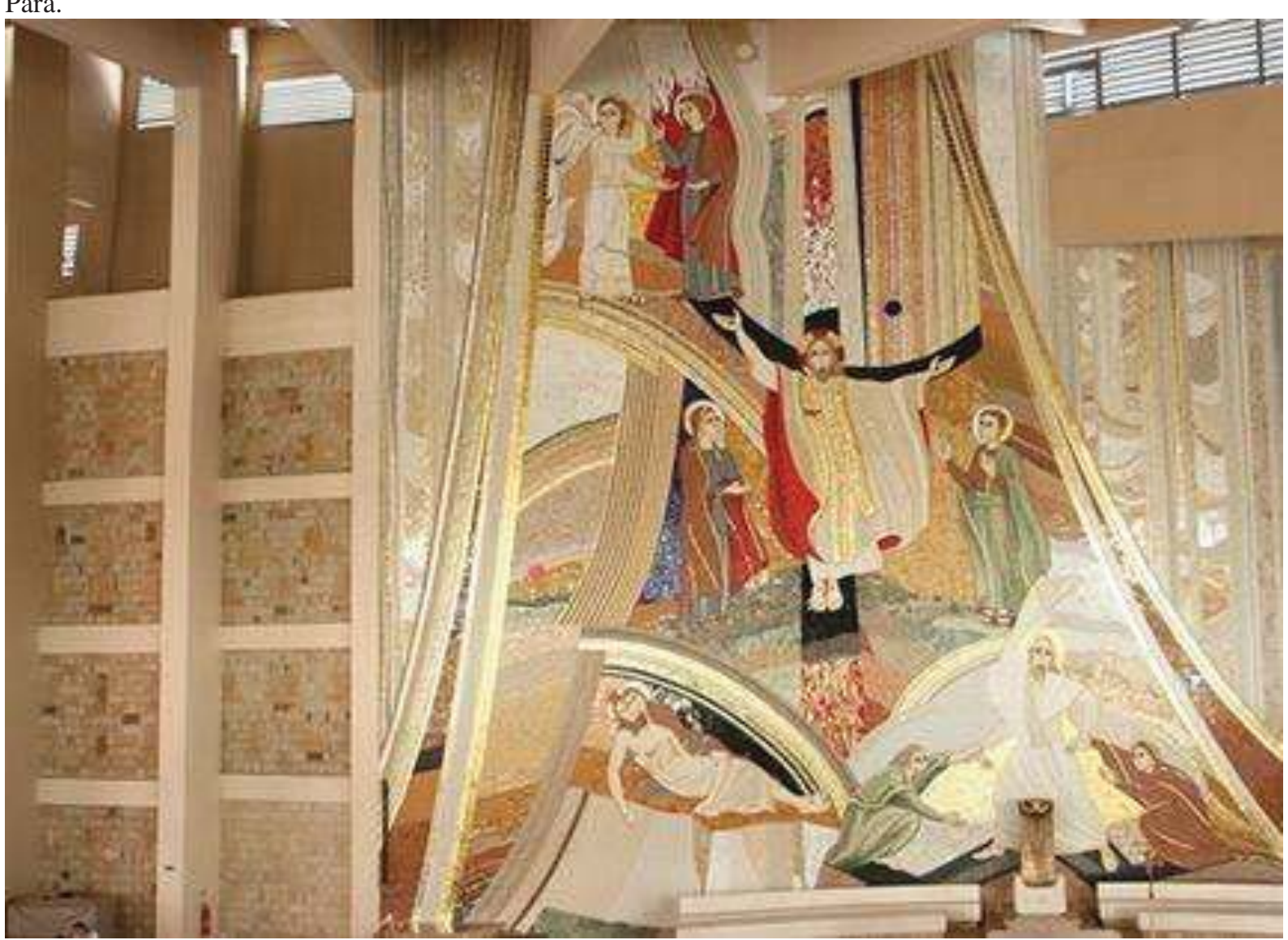

Fonte: Acervo do Centro Aletti - Roma, Itália. Disponivel em: <http://www.centroaletti.com/ita/opere/America-altro/129.htm>. Acesso em 13/01/2017.

No reconhecimento do campo de pesquisa e na tessitura das relações com alguns sujeitos que visitam o templo, é possivel obter de modo preliminar algumas impressões, entre elas é que se observa que além de oferecer outras experiências de culto, o mosaico possui um objetivo que é eminentemente arquitetônico e doutrinal. A imagem, se observada em seu conjunto, parece oferecer uma espécie de escritura ${ }^{6}$ para leigos, e oferece intercâmbios de

\footnotetext{
${ }^{6}$ Expressão utilizada pelo Papa Gregório I que viveu em meados do século VI d.C. Referiu-se a importancia do uso das imagens nos templos religiosos com esta afirmação: "A pintura pode fazer pelos analfabetos o que a escrita faz pelos que sabem ler", acentuando o caráter pedagógico do uso de imagens nas Igrejas tendo em vista os aspectos pastorais e doutrinários. Cf. DENZINGER, Henrich; HÜNERMANN, Peter — El Magisterio de la
} 
sentidos entre arquitetura, beleza artística, e espiritualidade, elementos que indicam traços de subjetividades a serem analisados.

As imagens são formas artísticas de comunicação de linguagem sobre algumas realidades, que trazem em si uma superação da linguagem literal para uma linguagem interpretada de uma determinada cena (de algum lugar) ou contexto. A questão que se coloca é como traduzir a intenção discursiva do autor presente na obra de arte? É possível que a sua elucidação esteja no conhecimento do contexto histórico-cultural em que a obra foi produzida, pois o sagrado com seus ritos e liturgias "se constituem dentro de uma história não metafórica, na pervivência de seu sentido originário porque sobrevivem através das gerações vindouras". (BENJAMIN, 2008, p.28).

Para Burke (2009) tal empreitada se define como tradução cultural e pode ser entendida como processo interpretativo que visa o entendimento de objetos estrangeiros no sentido da tradução strictu sensu de obras escritas. E o que se pretende é justamente analisar a rede de significados construídos a partir da relação entre o mosaico e os sujeitos que visitam o templo.

Para Baudrillard (1991) a imagem não se restringe apenas à visão de reprodutibilidade da natureza fatual, mas de um real intrínseco, de simulacros e simulações em que o imaginário e o imaterial estão inseridos na sua produção, na sua participação na sociedade e na cultura, assim como na sua fruição. Numa perspectiva amazônica, essas ocorrências sobrevivem ao longo das épocas onde o sagrado como momento separado se inscreve não somente no âmbito do maravilhoso ou mesmo do metafórico, mas indicam como sua permanência subsiste em expressões artísticas.

\section{2-LEITURA ICONOGRÁFICA E INTERPRETAÇÃO ICONOLÓGICA EM PANOFSKY}

Panofsky conceitua iconografia "como ramo da história da arte que trata do tema ou mensagem das obras de arte em contraposição à sua forma"”. O seu método se constitui basicamente em três etapas a serem considerados na analise e na avaliação das obras de arte, particularmente nas pinturas, que são respectivamente: o nível pré-iconográfico, o nível iconográfico e o nível iconológico.

Iglesia. Enchiridion Symbolorum Definitionum et Declarationum de Rebus Fidei et Morum. Segunda edición corrigida. Barcelona: Herder, 2000.

${ }^{7}$ Cf. PANOFSKY, Erwin. Significado nas artes visuais. Ed. Perspectiva S.A., São Paulo, 2011, p.47. 
O primeiro nível trata da identificação de certas configurações de linha e cor, e de elementos sólidos como pedra de forma peculiar, que no conjunto da obra podem representar homens, animais, ambientes, casas, ferramentas, etc. $\mathrm{O}$ reconhecimento desses elementos considera a relação mútua que estas representações têm com os acontecimentos, e da percepção de algumas qualidades expressionais da pintura, por ex. o caráter pesaroso de um gesto ou de uma paisagem de interior. Neste nível "o mundo das formas puras assim reconhecidas como portadoras de significados primários ou naturais pode ser chamado de mundo dos motivos artísticos. Uma enumeração destes motivos constituiria uma descrição pré-iconográfica de uma obra de arte." 8

No segundo nível, o objetivo é descobrir o conteúdo temático, isto é, o significado convencional da obra de arte. Trata-se de uma análise do mundo inteligível, que mobiliza conhecimento prévio das tradições culturais, das fontes literárias da época em que a obra foi produzida. São necessários ainda o conhecimento de símbolos, das alegorias e personificações que nominam e classificam uma figura ou um acontecimento. Ademais, identifica-se o tema, o autor, os personagens, o momento representado e o contexto em que ocorreu o episódio.

No terceiro nível, que Panofsky designa como "iconografia no seu sentido mais profundo" ou de "iconografia interpretativa", é permitido ao interprete traduzir os acontecimentos narrados pela imagem, compreendendo o seu significado no contexto em que ocorreram. É o significado intrínseco ou conteúdo, que é “apreendido pela determinação daqueles princípios subjacentes que revelam a atitude básica de uma nação, de um período, de uma classe social, crença religiosa ou filosófica - qualificados por uma personalidade e condensados numa obra." ${ }^{9}$ O papel interpretativo do terceiro nível é justamente o de explicar o sentido último da obra de arte, entendendo a que expectadores ela se dirige, ao lugar para onde ela foi pensada e porque ela foi constituída de determinados modos e mensagens. Os métodos descritos, porém, não estão divididos tão claramente em relação a aplicação da metodologia, como alerta Panofsky:

Devemos, porém ter em mente que essas categorias nitidamente diferenciadas, que no quadro sinóptico parecem indicar três esferas independentes de significado, na realidade se referem a aspectos de um mesmo fenômeno, ou seja, obra de arte como um todo. Assim sendo, no trabalho real, os métodos de abordagem que aqui aparecem como três operações de pesquisa irrelacionadas entre si, fundem-se num mesmo processo orgânico e indivisível. 10

\footnotetext{
${ }^{8}$ Id. Op. cit.,.p. 50.

${ }^{9}$ Id. Op. cit.,.p. 52.

${ }^{10}$ Id. Op. cit.,.p. 64.
} 


\section{3-LEITURA ICONOGRÁFICA E INTERPRETAÇÃO ICONOLÓGICA}

\section{3-1-A Anunciação do Anjo à Maria}

O Anuncio do Anjo à Maria é a primeira imagem a ser analisada. Esta narrativa encontra-se no texto bíblico, especificamente no Novo Testamento, em Lc 1, 26-38. ${ }^{11}$ Pois bem, ao olhar para cima, observa-se que um rolo de livro desce em forma de pergaminho sobre a cabeça da Virgem Maria. A princípio, o pergaminho apresenta-se em cor branca, que representa o Espirito Santo, que desce na Palavra de Deus, e envolve-a.

$\mathrm{Na}$ imagem, observa-se que do lado direito, por detrás da Virgem, as pedras do mosaico descem em forma de um pergaminho, e querem significar que todo o universo participa do momento em que ela aceita ser a Mãe do Filho de Deus. Já do lado esquerdo, observa-se que o Anjo aponta com o dedo direito para o céu, indicando que a palavra que ele trás consigo, vem do além, onde está Deus. E ela, a Virgem Maria, acolhe a Palavra de Deus, na voz do Anjo.

Fig. 2 - O Anuncio do Anjo à Virgem Maria. Mosaico, na abside do altar central da Igreja Catedral da Diocese de Castanhal, no Estado do Pará.

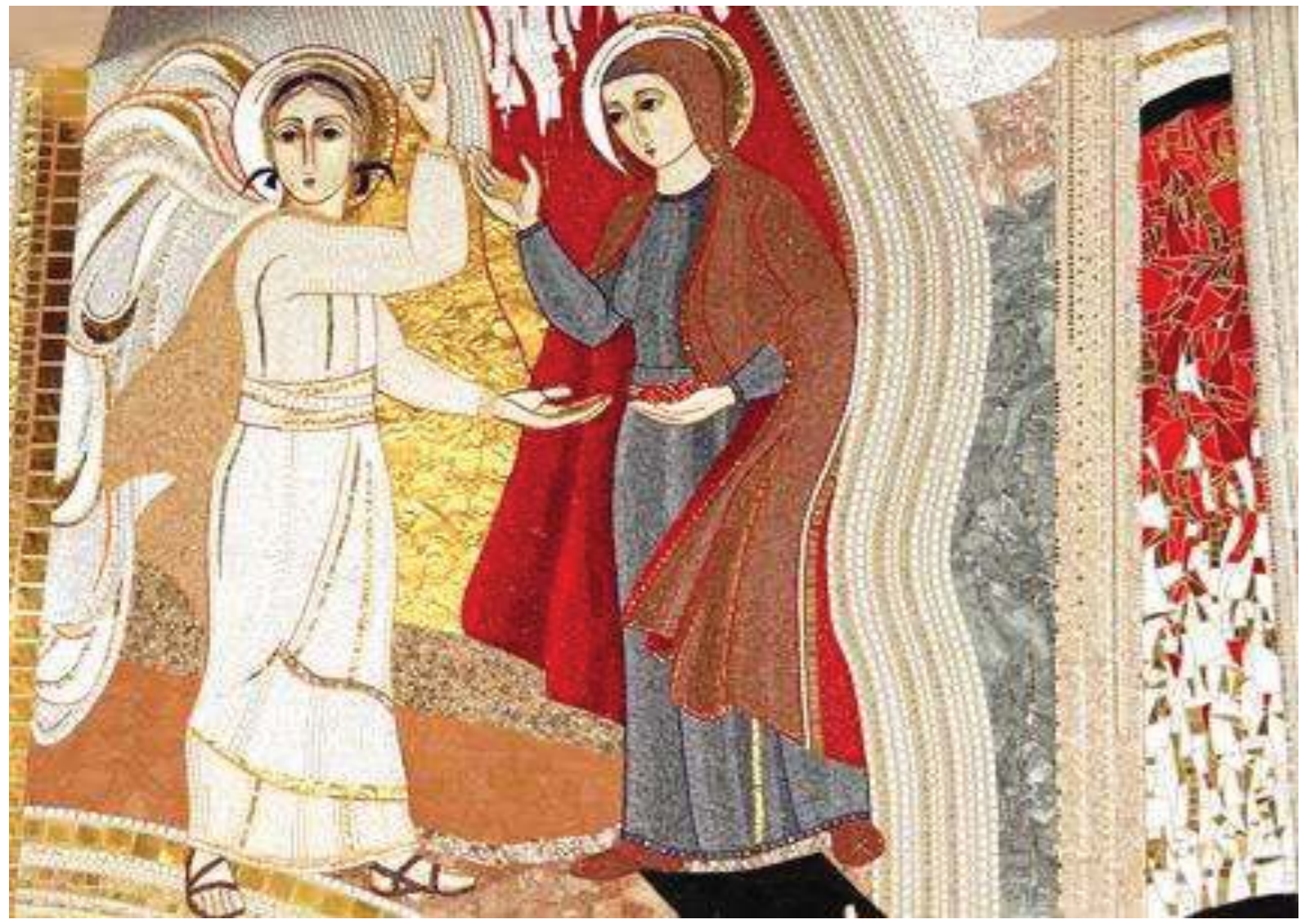

Fonte: Acervo do Centro Aletti - Roma, Itália.

Disponivel em: <http://www.centroaletti.com/ita/opere/America-altro/129.htm>. Acesso em 13/01/2017.

\footnotetext{
${ }^{11}$ Cf. Bíblia de Jerusalém. São Paulo: Paulus, 2002.
} 
A imagem com suas figuras, fatos e personagens nela representados, numa perspectiva cristã, constitue por sua própria natureza, a narrativa de um acontecimento importante na história das alianças que Deus fez com o seu povo, o novo Israel. Desse modo, a imagem conduz a produções de redes de significados que evidencia uma relação entre a consciência da realidade e o ethos religioso. Segundo tal compreensão, a fé, não se trata de uma conquista, nem tanto de um resultado das boas obras dos sujeitos que as realizam, e se assim o fosse, somente alcançariam os melhores. Analisando de outro modo, a todos é permitido fazer a experiência da fé. Assim, na imagem da Virgem que acolhe a palavra, figura um modelo a ser imitado, por todo cristão.

Olhando novamente para a imagem do mosaico, observa-se que a Virgem trás em suas mãos um novelo vermelho, que indica que está tecendo sua carne ao do verbo divino que dela irá nascer. Maria está tecendo os fios do novelo, que começam no pergaminho, onde está sendo tecido em sua carne e em seu sangue. Observe-se que aos pés de Maria, existe ainda um plano de cor preta, que indica que com o pé, ela participará do mistério da cruz do filho.

Analisando novamente, na mediação entre a consciencia da realidade e o ethos religioso, esta imagem faz referencia a todos aqueles que escutam a palavra. Trata-se de um ato que é simultaneamente escuta e reflexão, com vistas a uma prática de vida. Há um conflito constante entre o olhar e o ouvir, na medida em que se constata que os sujeitos estão mais habituados ao olhar, ao passo que na tradição bíblica do antigo testamento os personagens estavam habituados a ouvir.

Enfim, para o fiel que participa das celebrações na Igreja Catedral, o mosaico possui uma profunda relação com o mistério, celebrado na liturgia. $\mathrm{O}$ olhar que observa os detalhes de combinação geométrica das pedras do mosaico, nota o intercambio entre humano e o divino, pois, se para ter a compreensão do tema seja necessário separar os elementos constitutivos da obra, pelo contrário, na liturgia esta separação é tomada na imagem de um Deus que une, tal como mostram as narrativas bíblicas sobre uma história da salvação e das alianças que Deus fez com o seu povo.

\section{3-2-A Crucificação de Jesus}

A imagem a ser analisada nesta etapa está relacionada ao episodio da Crucificação de Jesus, tal como a narrativa bíblica assim o descreve: "Vendo Jesus a sua Mãe e junto dela o discípulo que ele amava, disse à sua Mãe: Mulher, eis aí o teu filho. Depois disse ao 
discípulo: Eis aí a tua Mãe. E, desta hora em diante, o discípulo a levou para sua casa" (Jo 19, 26-27).

$\mathrm{Na}$ abside mariana, ao lado esquerdo, encontra-se Maria, junto à cruz. Ela está com a mão no rosto, um antigo gesto presente nas iconografias cristãs, e indica dúvida e perplexidade, haja vista que o anjo lhe anunciara que seria mãe de alguém que seria grande, e posteriormente, o viu morrer na cruz. Todavia, pela imagem, os fiéis observam que o filho ensina à Mãe o último grau de sabedoria, o sentido da fraqueza humana, de ser vencido, derrotado e morto. Indica que a experiência do amor, pode converter todas estas realidades por uma oferta livre de si mesmo. Em outras palavras, não existe situação obscura que o homem não consiga superar.

Fig. 3 - A Crucificação de Jesus. Mosaico, na abside do altar central da Igreja Catedral da Diocese de Castanhal, no Estado do Pará.

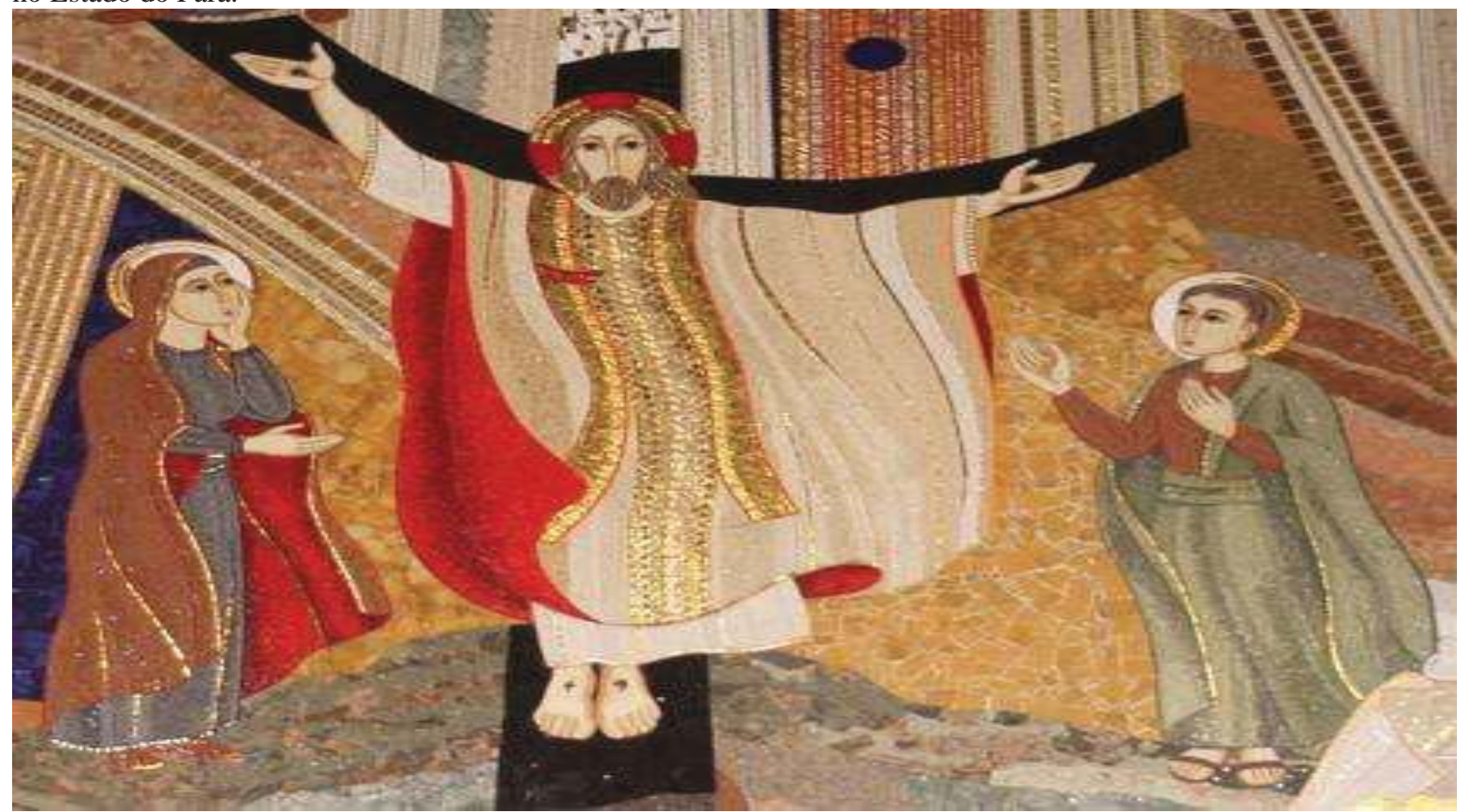

Fonte: Acervo do Centro Aletti - Roma, Itália. Disponivel em: <http://www.centroaletti.com/ita/opere/Americaaltro/129.htm>. Acesso em 13/01/2017.

A primeira vista, na perspectiva dos fiéis, parece simples que a Mãe de Deus, Maria, seja alguém excepcional por ser a Mãe do Salvador. Mãe de Deus significa que ela gerou na própria carne, o Filho de Deus, que assumiu uma dimensão de humanidade, daquele que se fez verdadeiro Deus e verdadeiro homem. Mas quem é Deus? O apóstolo João $(1 \text { Jo } 4,8)^{12}$ em sua sua carta responde afirmando que Deus é amor, e por isso, fez oferta de si mesmo, por meio do sacrificio da cruz. Desse modo, observando a imagem de Maria, aos pés da cruz, ela

\footnotetext{
${ }^{12}$ Cf. Bíblia de Jerusalém. São Paulo: Paulus, 2002.
} 
contempla em certo sentido sua carne e humanidade na experiência do filho, que é vivida como Deus, e de como cada pessoa é convidada a viver nesta dimensão a experiência do amor.

Ao centro da abside, é possível observar o Cristo pregado à Cruz. Na imagem, impressiona a forma como ele está retratado. Acredita-se que esta imagem tenha relação com o contexto histórico dos séculos V e VI da Era Cristã, quando surgiram as primeiras imagens dos crucifixos. Observa-se que o Cristo não está desnudo, ou mesmo trajando roupas de farrapos. Pelo contrário, apresenta-se vestido com trajes de sumo sacerdote.

Os primeiros cristãos assim o representaram não porque tivessem medo da cruz, mas porque imaginaram que as pessoas pensassem que ali estivesse apenas um bom homem, um filantropo, ou alguém que amasse as pessoas, ou mesmo um herói. O objetivo do artista era o de retratar Jesus como filho de Deus. Ou seja, o Cristo Crucificado é Sumo Sacerdote, pois é ele quem realiza o sacrifício que une a humanidade ao Pai, e somente ele podia passar por este véu de sofrimento, porque sabia que Deus o ressuscitaria. Por isso, o Cristo é retratado crucificado, mas apresenta-se poderoso, como sacerdote. Por sua morte e ressurreição, realiza um sacrifício universal. Assim, quando observada a distância, tem-se a visão de Cristo que está simultaneamente com as mãos pregadas e de braços abertos, numa postura de alguém que reza e que acolhe de forma plena e total.

Por fim, para os fiéis que frequentam a Igreja Catedral, esta imagem do Cristo é o modelo a ser seguido. A imagem assume uma personificação; é como se o Cristo, ele mesmo, acolhesse as pessoas que chegam até o templo; e os sujeitos se reconhecem numa especial predileção. Por isso, os fiéis tem a consciencia de que são Povo de Deus, e que o Cristo estará sempre de braços abertos para recebe-los. Há uma conformação do sacrifício de Cristo ao sacrifício da vida das pessoas, onde os sujeitos poderão apoiar seus corpos cansados, os sofrimentos, os pecados, o desespero, mas também a alegria. Enfim, trata-se de uma acolhida que se atualiza por meio da liturgia.

\section{4-PERSPECTIVAS PARA A PESQUISA: OUTROS APROFUNDAMENTOS.}

É consenso de que de a Iconografia é o estudo das imagens enquanto descrição de representações produzidas pela linguagem. Pois se trata de uma descrição linguística que se constitui como método porque permite o conhecimento relativamente profundo do misterium tremendum ${ }^{13}$ presente na obra de arte. Assim, pela iconografia é possivel analisar, classificar,

${ }^{13}$ Expressão encunhada por Rudolf Otto (2007) para explicar a sensação causada naqueles que fazem experiências de sentimentos tipicamente irracionais e simultaneamente de distanciamento e atração. É desta 
descrever e interpretar a mensagem mais profunda na obra de arte.

Desse modo, trata-se de um método que procura construir perspectivas teóricas de análise da realidade, sob um olhar suspeitável pelas obras, porque a obra de arte está vinculada a realidade social. Por conseguinte, ao elaborar uma perspectiva iconográfica no âmbito de uma tradução cultural, buscam-se preliminarmente nos estudos realizados em (Casimiro, 2003; Benjamin, 2008; Bauer e Gaskell, 2002; Rahde, 2006; Samain, 1999; Santos, 2010) outras descontinuidades para a análise iconográfica.

Numa perspectiva antropológica, compreende-se a tradução cultural como processo de implicação e discussão de problemas relacionados ao alcance da realidade da construção cientifica da arte, "bem como da relatividade e da comensurabilidade de diferentes formas de conhecimento, procurando equacionar as relações entre linguagens diferentes e uma perspectiva disciplinar". O conceito garante uma coesão interna entre língua, cultura e ciência. (FAULHABER, 2008).

Em relação à pesquisa, a abordagem parece propor, à primeira vista, somente uma iconografia como descrição do sagrado. Mas compreensões outras têm demonstrado que a iconografia é uma ciência que mobiliza outros saberes especializados como Estética, Linguística, Cultura, Antropologia, Filosofia e Teologia. De fato, tais saberes colocam questões que carecem ser observadas numa perspectiva de descontinuidade iconográfica, sem, contudo, desconsiderar a atmosfera em que ela se constituiu.

Em outras palavras, o método iconográfico pode ser subsidiado por outros intercâmbios e compreensões, a partir dos diversos tipos de influencia sobre a obra tais como a relação entre arte, artista e psicanálise, bem como "a influencia das ideias filosóficas, teológicas e politicas; os propósitos e inclinações individuais dos artistas e patronos; a correlação entre os conceitos inteligíveis e a forma visível que assume em caso especifico." ${ }^{\text {"4 }}$

Para Santos (2010) novas possibilidades rompem com formações cristalizadas, e isto configura de certo modo um problema epistemológico, pois o saber teológico, muito embora possua uma epistemologia própria, está assentado numa revelação divina, de verdades que não se provam pela ciência. Todavia, a iconografia cristã é testemunho de como o homem traduziu em arte um conjunto de expressões artísticas a serviço da fé, mas que são significadas na relação do homem com o mistério, e que evidencia que a experiência do sagrado se realiza na experiência humana.

experiência religiosa que resulta a mística, que se reflete qualitativamente na inspiração pelas qualidades transcendentais da divindade.

${ }^{14}$ Cf. PANOFSKY, Erwin. Significado nas artes visuais. Ed. Perspectiva S.A., São Paulo, 2011, p.53. 
De fato, tal concepção forjou uma compreensão de beleza e de estética de arte cristã acerca do patrimônio teológico espiritual do ocidente e do oriente. Contudo, é importante acentuar que a revelação divina precisou da arqueologia e da hermenêutica para fazer-se compreender no contexto histórico em que foi anunciada; e que, portanto, esses saberes são produções humanas. Assim, pode-se inferir que o caráter humano está impregnado não somente na produção artística como obra fatual, mas na interpretação que o artista faz nascer por ela.

Para formular uma critica sobre as etapas do processo de análise e interpretação do método proposto por Panofski, Luís Casimiro propõe a componente geométrica como método complementar de interpretação das obras. Na perspectiva deste autor, este método completa as lacunas deixadas pela analise que estas etapas não realizam, nem contemplam, qualquer referência à outra vertente da análise que se pode ter sobre as obras de arte, em particular sobre a pintura.

O método de esquema geométrico da composição que consiste em analisar as pinturas de forma a efetuar a leitura do esquema geométrico de composição que esteve na gênese estrutural da pintura. Este esquema é o resultado da conjugação do delineamento definidor da perspectiva, com outras linhas de força e figuras geométricas utilizadas pelo pintor como apoio de personagens e objetos importantes, com a finalidade de reforçar o significado da mensagem iconográfica. ${ }^{15}$

Segundo o autor, o conhecimento do contexto histórico-cultural das obras perpassa pelo domínio das perspectivas matemáticas que estão presentes nas obras de arte. Portanto, trata-se de uma análise que restaura o caráter de acontecimento da obra de arte nas pinturas. No domínio das leis da perspectiva, "os pintores adquirem a capacidade técnica para realizar algo nunca alcançado: libertar o espaço tridimensional dos vínculos que o ligavam à superfície do quadro." 16

Todavia, o método crítico de interpretação proposto por Casimiro refuta o método de análise de Panofski, mas não abarca a explicação das categorias discursivas e da intencionalidade artística como traços na obra. Igualmente, não elabora uma perspectiva iconográfica de tradução cultural, pois centram suas reflexões somente no caráter das formas, presentes na pintura. Daí, conclui-se que a compreensão comum acerca de uma tradução não pode se sustentar, porque vista de um ponto de vista histórico, a imagem fatual se movimenta, e escapa a qualquer predeterminação geométrica.

${ }^{15}$ CASIMIRO, Luís Alberto. Quatro pinturas do retábulo da Sé de Lamego: análise iconográfica e geométrica. Revista da Faculdade de Letras CIÊNCIAS E TÉCNICAS DO PATRIMÓNIO. Porto, 2003 I Série vol. 2, pp. 446.

${ }^{16}$ Id. Op. cit.,. 
Benjamin (2008) propõe algumas reflexões pontuais, em seu conceito de traduzibilidade, ao restaurar à obra de arte o caráter de acontecimento. Por ela entende-se que a compreensão do contexto cultural onde está o artista não passa tanto pelos traços matemáticos axiomaticamente definidos, mas pelo devir histórico das obras. Sua comunicabilidade não está condicionada a um "público ideal", mas se firma no pressuposto da existência e da essência do humano.

De fato, esta percepção de tradução cultural proposta por Benjamin, inaugura uma nova perspectiva de abordagem, pois "não é metáfora, mas sim literalmente que se deve entender uma obra de arte" ${ }^{17}$, que a história mostra-nos como as grandes obras de arte “descenderam das suas fontes [...] e revela-nos o período fundamentalmente eterno da sua sobrevivência através das gerações vindouras."18 A tarefa do tradutor consiste na compreensão dos ciclos de vida presentes nas obras de arte.

Esta perspectiva de tradução cultural está relacionada à iconografia como método de interpretação no sentido de que a compreensão dos fenômenos relacionados à vida se inscreve numa perspectiva de finalidade. Em última análise, "todos os fenômenos vitais assim como as suas finalidades particulares e isoladas não surgem para serem úteis à vida, mas sim para dar expressão à sua natureza e para apresentar aquilo que ela significa."19

Simonian (2006) propõe uma aproximação das categorias de imagem no desenvolvimento da ciência entre os séculos XIX e XX. Mostra que o uso da imagem é anterior ao uso da fotografia como imagem em movimento por seus atores que produziram os registros iconográficos como relato da biosociodiversidade encontrada na região amazônica. Inicialmente tratava-se de uma iconografia produzida por seus viajantes, ensaístas e cartógrafos que por aqui passaram e que produziram um conjunto de imagens muito anterior à fotografia. No período, a iconografia foi à expressão mais cara de registro e de tradução cultural, seja por suas contribuições às ciências e à botânica, seja por suas memorias de experiências vividas no interior das comunidades tradicionais.

Por tudo o que foi mencionado, o que se pretende é construir perspectivas teóricas como análise da realidade, pelo olhar suspeitável das obras de arte, considerando os diversos modos pelos quais elas se vinculam a realidade social. Pretende constituir-se como descrição de acontecimento numa perspectiva de epistemologia total, sem desconsiderar sua

\footnotetext{
${ }^{17}$ BENJAMIN, Walter. A tarefa do tradutor: quatro edições para o português. Uma organização de Lucia Castello Branco. Belo Horizonte: Fale/UFMG, 2008, p.28.

${ }^{18}$ Id. Op. cit.,.

${ }^{19}$ Id. Op. cit.,
} 
complexidade, na qual as diversas áreas dos saberes se mobilizam na compreensão dos problemas colocados pela pesquisa.

\section{REFERÊNCIAS:}

BAUDRILLARD, Jean. Simulacros e simulação. Lisboa: Relógio d'Água, 1991. BAUER, Martin W.; GASKELL, Georg. Pesquisa qualitativa com texto, imagem e som: um manual prático. Tradução de Pedrinho Guareschi. Petrópolis, Rio de Janeiro: 2002.

BENJAMIN, Walter. A tarefa do tradutor: quatro edições para o português. Uma organização de Lucia Castello Branco. Belo Horizonte: Fale/UFMG, 2008.

BIBLIA DE JERUSALÉM. São Paulo: Paulus, 2002.

BURKE, Peter e HSIA, R. Po-chia (orgs), tradução de Roger Maioli dos Santos. A tradução cultural nos primórdios da Europa Moderna. São Paulo: Editora UNESP, 2009.

CASIMIRO, Luís Alberto. Quatro pinturas do retábulo da Sé de Lamego: análise iconográfica e geométrica. Revista da Faculdade de Letras CIÊNCIAS E TÉCNICAS DO PATRIMÓNIO. Porto, 2003 I Série vol. 2, pp. 443-472.

DENZINGER, Henrich; HÜNERMANN, Peter - El Magisterio de la Iglesia. Enchiridion Symbolorum Definitionum et Declarationum de Rebus Fidei et Morum. Segunda edición corrigida. Barcelona: Herder, 2000.

DINIZ, Davidson de Oliveira. Walter Benjamin e as Passagens: uma narratividade poética do histórico. Cadernos Benjaminianos, Belo Horizonte, v.1, volume 1, p.2-19, 2009.

FAULHABER, Priscila. Etnografia e tradução cultural em Antropologia. Museu Paraense Emílio Goeldi/ Museu de Astronomia e Ciências Afins. Disponível em <http://www.scielo.br/pdf/bgoeldi/v3n1/v3n1a02.pdf>. Acesso em 08 dez. 2015.

GOLDENBERG, Mirian. A arte de pesquisar: como fazer pesquisa qualitativa em Ciências Sociais $-8^{\mathrm{a}}$ ed. Rio de Janeiro: Record, 2004.

IBGE - Fundação Instituto Brasileiro de Geografia e Estatística. Disponível em: < http://cod.ibge.gov.br/1H0A > .Acesso em: 22 Fev. 2017).

OTTO, Rudolf. O Sagrado. Os aspectos irracionais na noção do divino e sua relação com o racional. Tradução brasileira de Walter O. Schlupp. EST - Sinodal - Vozes: São Leopoldo Petrópolis, 2007.

PANOFSKY, Erwin. Significado nas artes visuais. São Paulo: Perspectiva, 2011.

RAHDE, Maria Beatriz Furtado. Comunicação visual e imaginários culturais iconográficos do contemporâneo. Revista Compos: Associação Nacional dos Programas de Pós-graduação em Comunicação, Rio Grande do Sul, p.02-13, 2006.

SAMAIN, Etienne. Um retorno à câmara clara: Rolando Barthes e antropologia visual. In: 